\title{
A Rare Complication of Dengue Fever- Symmetrical Peripheral Gangrene
}

\author{
Shaik Sulaiman Meeran¹, Mani Agila Saravanan², Geetha Sivaramalingam³, Suganthi Varadharajan Sangeetha4, \\ Balaji Thenrajan ${ }^{5}$
}

\begin{abstract}
${ }^{1}$ Professor, Department of Medicine, Government Royapettah Hospital/Government Kilpauk Medical College, Chennai, Tamilnadu, India. ${ }^{2}$ Assistant Professor, Department of Medicine, Government Royapettah Hospital/Government Kilpauk Medical College, Chennai, Tamilnadu, India. ${ }^{3}$ Assistant Professor, Department of Medicine, Government Royapettah Hospital/Government Kilpauk Medical College, Chennai, Tamilnadu, India. ${ }^{4}$ Assistant Professor, Department of Medicine, Government Royapettah Hospital/Government Kilpauk Medical College, Chennai, Tamilnadu, India. ${ }^{5}$ Assistant Professor, Department of Medicine, Government Royapettah Hospital/Government Kilpauk Medical College, Chennai, Tamilnadu, India.
\end{abstract}

\section{INTRODUCTION}

Among the arboviral infections, dengue fever is one of the most important. The presentation of dengue fever varies widely from asymptomatic to mild infection to severe manifestations like dengue hemorrhagic fever, dengue shock syndrome and multiorgan failure. Here we report a 13-year-old female who was admitted for dengue infection, later developed symmetrical peripheral gangrene of both upper and lower limbs. Doppler ultrasonography of both upper and lower limbs was normal, FDP: $>20 \mu \mathrm{g} / \mathrm{ml}$. Patient was managed conservatively with IV fluids, LMW heparin, broad spectrum IV antibiotics, and warming of extremities. Patient improved with no further progression of gangrene. Symmetrical peripheral gangrene is a rare entity which presents with gangrene of two or more sites due to symmetrical distal ischemic damage without any large vessel obstruction or vasculitis. ${ }^{1}$ It was first described by Hutchinson in the year $1891 .^{2}$ It is a manifestation of numerous systemic diseases and was thought to be a cutaneous manifestation of disseminated intravascular coagulation ${ }^{3}$. Uncommonly it is seen in infections, shock, drugs and toxins.

\section{PRESENTATION OF CASE}

A 13-year-old female presented to us with complaints of myalgia and fever for 4 days. On examination she was febrile (102 F), dehydrated, tachycardic $(120 / \mathrm{min})$ and hypotensive $(90 / 60 \mathrm{mmHg})$. Systemic examination was normal. IV line secured and normal saline started. Investigations revealed platelet count of 21,000. Dengue IgM was positive. After 2 days, it was noted that there was bluish discoloration of fingers and toes which progressively became gangrenous over the next few hours. But in the affected limbs, all the peripheral pulses were palpable. Local examination revealed cold, dry, wrinkled skin of both hands and feet. USG abdomen showed minimal ascites with GB wall oedema, Doppler ultrasonography of both upper and lower limbs were normal, echo showed no evidence of vegetation or thrombus. No growth in urine and blood cultures. FDP: $>20 \mu \mathrm{g} / \mathrm{ml}$, Fibrinogen: Normal, PTINR: 1.6, ANA profile: Negative. On the basis of clinical findings and investigation reports, a diagnosis of symmetrical peripheral gangrene was made. Patient was managed conservatively with IV fluids, LMW heparin, broad spectrum IV antibiotics, and warming of extremities. General condition improved with no further progression of gangrene. Vascular surgery consultation was taken.
Corresponding Author: Mani Agila Saravanan,

No. 5, Thuru Nagar,

Colony III Street, Vadapalani,

Chennai-600026, Tamilnadu, India.

E-mail: agilajeevamoni@gmail.com

DOI: $10.14260 / j e m d s / 2019 / 688$

Financial or Other Competing Interests: None.

How to Cite This Article:

Meeran SS, Saravanan MA, Sivaramalingam $G$, et al. A rare complication of dengue fever- symmetrical peripheral gangrene. J. Evolution Med. Dent. Sci. 2019;8(42):3177-3178, DOI: $10.14260 /$ jemds/2019/688

Submission 09-08-2019,

Peer Review 01-10-2019,

Acceptance 08-10-2019,

Published 21-10-2019. 


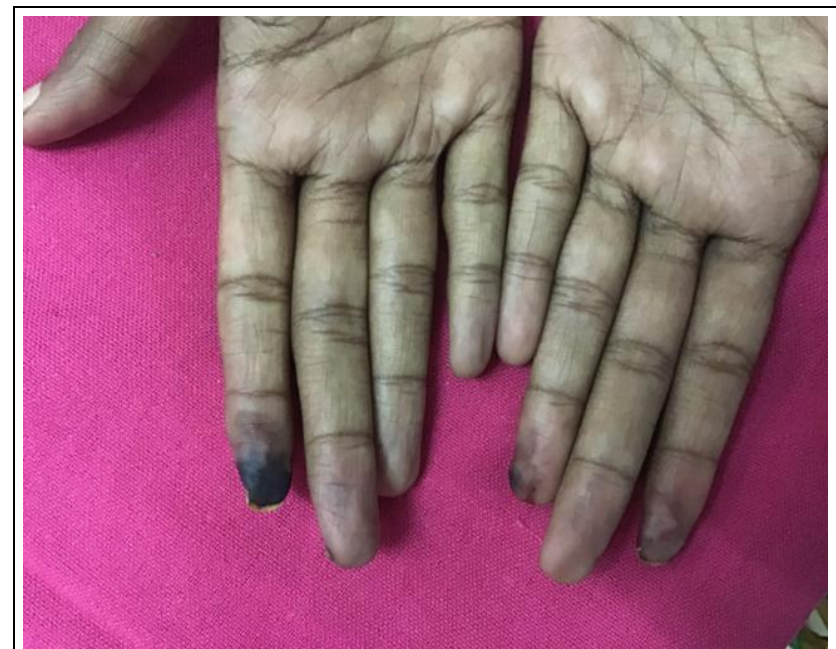

Figure 1. Symmetrical Peripheral Gangrene of Fingers

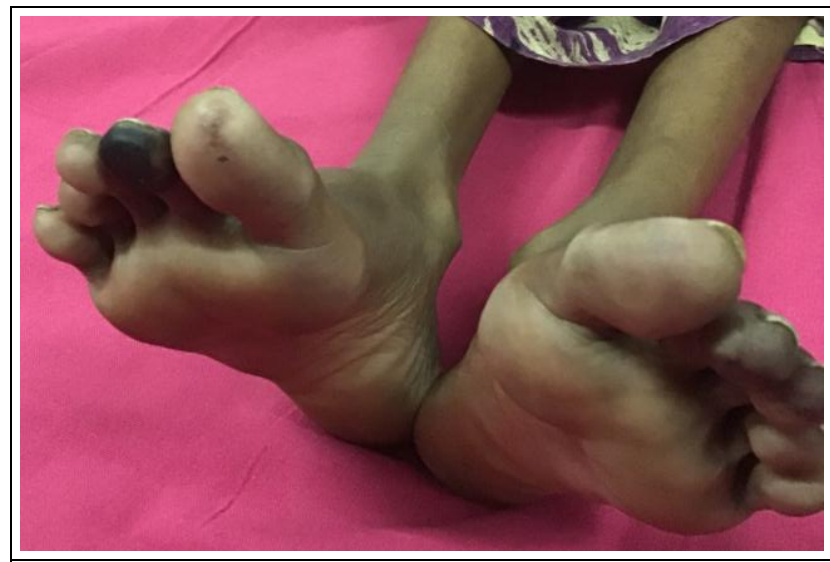

Figure 2. Symmetrical Peripheral Gangrene of Toes

\section{DISCUSSION}

Dengue infection presents with variety of symptoms. ${ }^{4}$ The hallmark of this infection is increased vascular permeability with coagulation disorder. Peripheral gangrene is seen in a wide variety of medical conditions but rarely in dengue. The pathogenesis of SPG may involve the Schwartzman's reaction, bacterial endotoxin release, platelet plugging in peripheral arterioles due to vascular collapse and DIC. The ischaemic changes begin distally and may advance proximally to involve the whole extremity. As soon as marked coldness, pallor and cyanosis of the acral parts of the body are seen, symmetrical peripheral gangrene should be suspected. The condition can rapidly progress to acrocyanosis and if not reversed, frank gangrene develops. Since the large vessels are not affected in symmetrical peripheral gangrene, distal pulses are spared. It is associated with high risk of amputation. It has been reported that successful treatment is anticoagulation with heparin, aspirin, tissue plasminogen activator infusion, epoprostenol and antibiotics. ${ }^{5}$ Symmetrical Peripheral Gangrene is a clinical syndrome of sinister prognostic implication, in terms of loss of life or limbs. Identification and treatment of etiological factors and treatment of Disseminated Intravascular Coagulation have remained the main stay of treatment.

\section{FINAL DIAGNOSIS}

Symmetrical Peripheral Gangrene Secondary to Dengue Fever.

\section{REFERENCES}

[1] Tripathy S, Rath B. Symmetric peripheral gangrene: catch it early! J Emerg Trauma Shock 2010;3(2):189-90.

[2] Hutchison J. Severe symmetrical gangrene of the extremities. Br Med J 1891;2:8-9.

[3] Sharma BD, Kabra SR, Gupta B. Symmetrical peripheral gangrene. Trop Doct 2004;34(1):2-4.

[4] Karunatilaka DH, De Silva JR, Ranatunga PK, et al. Idiopathic purpura fulminans in dengue hemorrhagic fever. Indian J Med Sci 2007;61(8):471-3.

[5] Parmar MS. Symmetrical peripheral gangrene: a rare but dreadful complication of sepsis. CMAJ 2002;167(9):10378. 